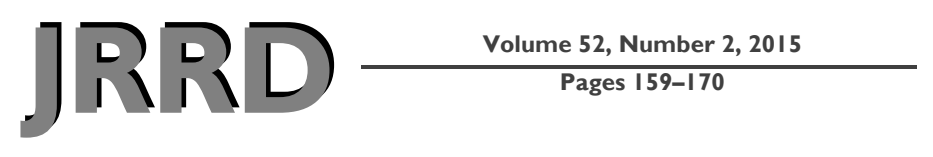

\title{
Lower-limb amputation and body weight changes in men
}

\begin{abstract}
Alyson J. Littman, PhD; ${ }^{1-2 *}$ Mary Lou Thompson, PhD; ${ }^{1,3}$ David E. Arterburn, MD, MPH; ${ }^{4}$ Erin Bouldin, PhD $;^{1-2}$ Jodie K. Haselkorn, MD $;^{2,5-6}$ Bruce J. Sangeorzan, MD ${ }^{6}$ Edward J. Boyko, MD ${ }^{1}$

${ }^{1}$ Seattle Epidemiologic Research and Information Center, Department of Veterans Affairs (VA) Puget Sound Health Care System, Seattle, WA; Departments of ${ }^{2}$ Epidemiology and ${ }^{3}$ Biostatistics, University of Washington, Seattle, WA; ${ }^{4}$ Group Health Research Institute, Seattle, WA; ${ }^{5}$ Multiple Sclerosis Centers of Excellence West, VA Puget Sound Health Care System, and Department of Rehabilitation, University of Washington, Seattle, WA; ${ }^{6}$ VA Center of Excellence for Limb Loss Prevention and Prosthetic Engineering, VA Puget Sound Health Care System, and Department of Orthopaedics and Sports Medicine, Harborview Medical Center, Seattle, WA
\end{abstract}

\begin{abstract}
Little is known about the relationship between lower-limb amputation (LLA) and subsequent changes in body weight. We conducted a retrospective cohort study using clinical and administrative databases to identify and follow weight changes in 759 males with amputation (partial foot amputation [PFA], $n=396$; transtibial amputation [TTA], $n=267$; and transfemoral amputation [TFA], $n=96$ ) and 3,790 men without amputation frequency-matched (5:1) on age, body mass index, diabetes, and calendar year from eight Department of Veterans Affairs medical care facilities in the Pacific Northwest. We estimated and compared longitudinal percent weight change from baseline up to 39 mo of follow-up in men with and without amputation. Weight gain in the $2 \mathrm{yr}$ after amputation was significantly more in men with an amputation than without, and in men with a TTA or TFA (8\%-9\% increase) than in men with a PFA (3\%-6\% increase). Generally, percent weight gain peaked at $2 \mathrm{yr}$ and was followed by some weight loss in the third year. These findings indicate that LLA is often followed by clinically important weight gain. Future studies are needed to better understand the reasons for weight gain and to identify intervention strategies to prevent excess weight gain and the deleterious consequences that may ensue.
\end{abstract}

Key words: adult, lower-limb amputation, men, obesity, partial foot amputation, toe amputation, transfemoral amputation, transtibial amputation, Veterans, weight change.

\section{INTRODUCTION}

An estimated 185,000 amputations are performed each year in the United States [1-3]. Excess body weight is a major concern for people with a lower-limb amputation (LLA) because it can have numerous deleterious consequences, including an increased risk of musculoskeletal pain, osteoarthritis, cardiovascular disease, falls and other injuries, impaired functional capacity, reduced prosthesis fit and function, and a diminished quality of life [4-8]. These consequences can in turn result in reduced activity levels and a cascade of events such as increased wheelchair use, a more sedentary lifestyle, greater healthcare utilization and costs, reduced ability to

\footnotetext{
Abbreviations: $\mathrm{BMI}=$ body mass index, $\mathrm{DCG}=$ diagnostic cost group, ICD-9 = International Classification of Diseases9th edition, LLA = lower-limb amputation, PFA = partial foot amputation, SCD = service-connected disability, TFA = transfemoral amputation, TTA = transtibial amputation, VA = Department of Veterans Affairs, VISN = Veterans Integrated Service Network.

*Address all correspondence to Alyson J. Littman, PhD; Seattle Epidemiologic Research and Information Center, VA Puget Sound Medical Center, 1100 Olive Way, Metropolitan Park West, Suite 1400, Seattle, WA 98101; 206-2774182; fax: 206-764-2563. Email: alyson.littman@va.gov http://dx.doi.org/10.1682/JRRD.2014.07.0166
} 
live independently, and increased burden on formal and informal caregivers [7-8].

A few older cross-sectional studies found that obesity was approximately two times more prevalent in persons with an LLA than in those without [9-10]. To our knowledge, only one longitudinal study has assessed weight change following LLA. This study included 87 individuals who underwent a dysvascular LLA [11]. Compared with 6 wk after amputation, body mass index (BMI) had increased by $1.4 \mathrm{~kg} / \mathrm{m}^{2}$ on average 12 mo postamputation, or about $4.5 \mathrm{~kg}(10 \mathrm{lb})$ for a person with a starting weight of $100 \mathrm{~kg}(220 \mathrm{lb})$ and height of $1.8 \mathrm{~m}(5 \mathrm{ft}$ $10 \mathrm{in}$.), providing support for the hypothesis that amputation leads to excess weight gain. Nevertheless, this study was small, did not include a comparison group of persons without amputation, and examined outcomes only in the first year after an amputation.

To better understand how an incident LLA may affect weight, observational studies are needed to describe typical weight trajectories to better understand the scope of the problem and ultimately to develop interventions to prevent unhealthy weight gain and improve health outcomes in this population. To this end, we conducted a retrospective cohort study with two primary aims: (1) to evaluate the relationship between incident amputation and body weight change in the $3 \mathrm{yr}$ after an LLA relative to a demographically similar population without an amputation and (2) to examine the extent to which weight change varied by level of amputation (i.e., no amputation vs partial foot amputation [PFA], transtibial amputation [TTA], and transfemoral amputation [TFA]) and BMI prior to surgery. We hypothesized that weight gain would be greater among those with amputation than without, and among those with an amputation, those whose mobility was more impaired, operationalized as those with a more proximal amputation. We were uncertain of how preamputation BMI might affect weight gain.

\section{METHODS}

\section{Population}

Data were obtained from the Department of Veterans Affairs (VA) Northwest Region database (Veterans Integrated Service Network [VISN] 20), which includes demographic characteristics and clinical and administrative medical record information on outpatient and inpa- tient encounter, vital sign, pharmacy, and laboratory data. VISN 20 is one of 21 VA networks and comprises eight medical centers (VA Puget Sound, Washington; Portland, Oregon; Spokane, Washington; Boise, Idaho; Walla Walla, Washington; Roseburg, Oregon; Anchorage, Alaska; and White Center, Oregon) and their communitybased outpatient clinics.

\section{Cohort of Individuals with Incident Amputation}

We considered for inclusion male VISN 20 patients who had an incident toe, foot, or leg amputation (International Classification of Diseases-9th edition [ICD-9] surgical codes: 84.10-84.17) between January 1, 1997, and December 31, 2008, and a plausible baseline weight ("baseline" and "plausible" defined subsequently) and one or more follow-up weight(s) occurring between $2 \mathrm{wk}$ and 39 mo (3.25 yr) after their baseline weight. We selected approximately 3 yr of follow-up to balance the desire for longer-term follow-up with the reality that for a relatively large fraction of patients, weights were not available 3 or more years after their amputation (e.g., due to death or lack of weight measures in the electronic medical record). Figure 1 presents exclusion criteria and numbers excluded for each reason. Briefly, we excluded women because they represented so few of all persons with an amputation. In order to limit our sample to a healthier population for whom a weight management intervention might be indicated, we excluded men who died or had a subsequent amputation within 18 mo of their index amputation. However, we included individuals who had two or more amputations within the initial $45 \mathrm{~d}$ postsurgical period who otherwise met the eligibility criteria noted previously. Their index amputation date was the date of their last amputation. Persons with amputation who had a subsequent major amputation 18 to 39 mo after their index amputation were censored at that time and no subsequent weights were included. Amputation etiology was inferred via diagnoses present at the time of the amputation. We created three mutually exclusive amputation groups based on the most proximal level of amputation: (1) PFA (ICD-9 84.11-84.12), (2) TTA (ICD-9 84.13-84.16), and (3) TFA (ICD-9 84.17).

\section{Cohort of Individuals Without Amputation}

To determine what the typical weight trajectory might have been in the absence of an amputation, we constructed a comparison group of men without lowerlimb loss (either prior to baseline or during follow-up) 


\section{Patients at one of 8 VA medical facilities in the Northwest US}

Amputee cohort

$$
\begin{aligned}
& \text { Incident lower limb amputation } \\
& \text { (ICD-9 codes: } 84.10-84.17 \text { ) } \\
& N=1753
\end{aligned}
$$

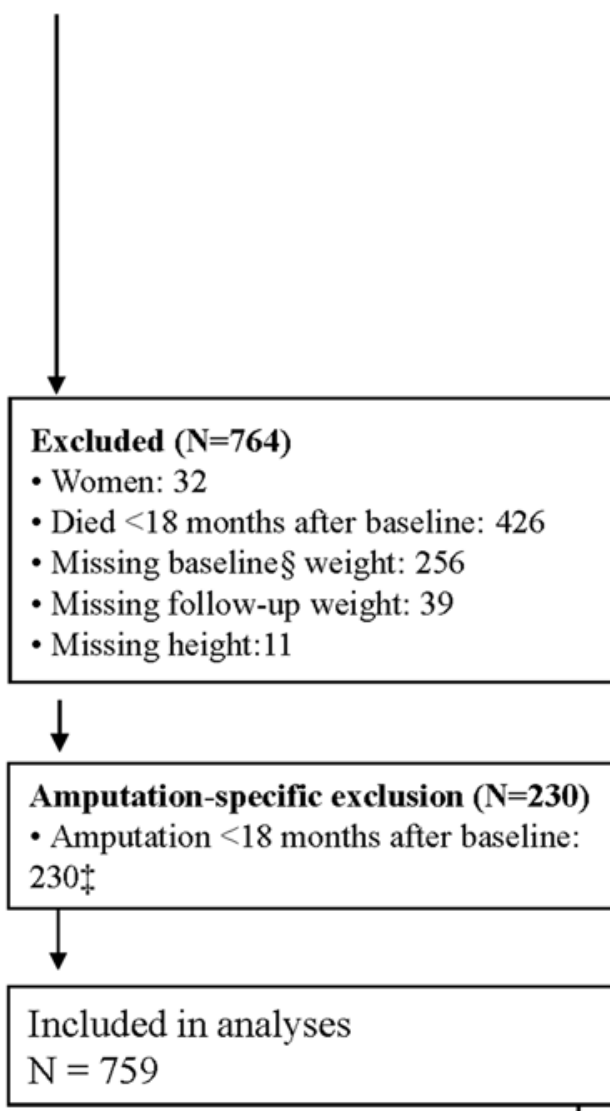

Excluded $(\mathrm{N}=764)$

en: 32

Died $<18$ months after baseline: 426

- Missing baseline§ weight: 256

- Missing follow-up weight: 39

Missing height:11

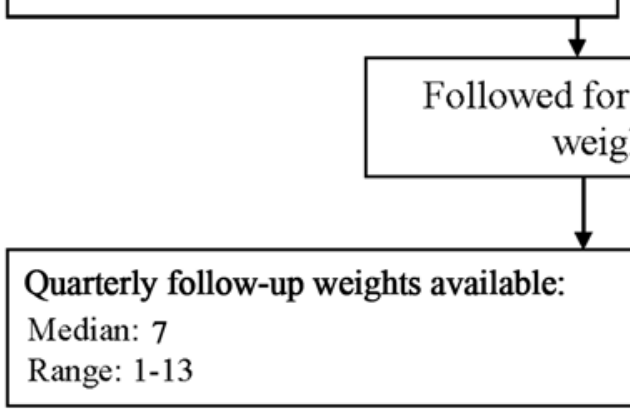

Nonamputee cohort

Men, aged 27-90, with no history of lower limb amputation, with baseline weight and height, $\geq 1$ follow-up weight, who lived at least 18 months after baseline $N=228,304$

Frequency matched $(5: 1)$ on:

- Age (27-55, 55-64, 65-74, 75-90 years)

- Calendar year (97-00, 01-02, 03-04, 05-06, and $07-08$ )

- Diabetes (yes/no, ICD-9 codes: 250.0-250.93)

- Body mass index $\left(<25,25-29.9, \geq 30 \mathrm{~kg} / \mathrm{m}^{2}\right)$

$N=3795$

\section{Excluded (n=5)}

- No match identified: 5

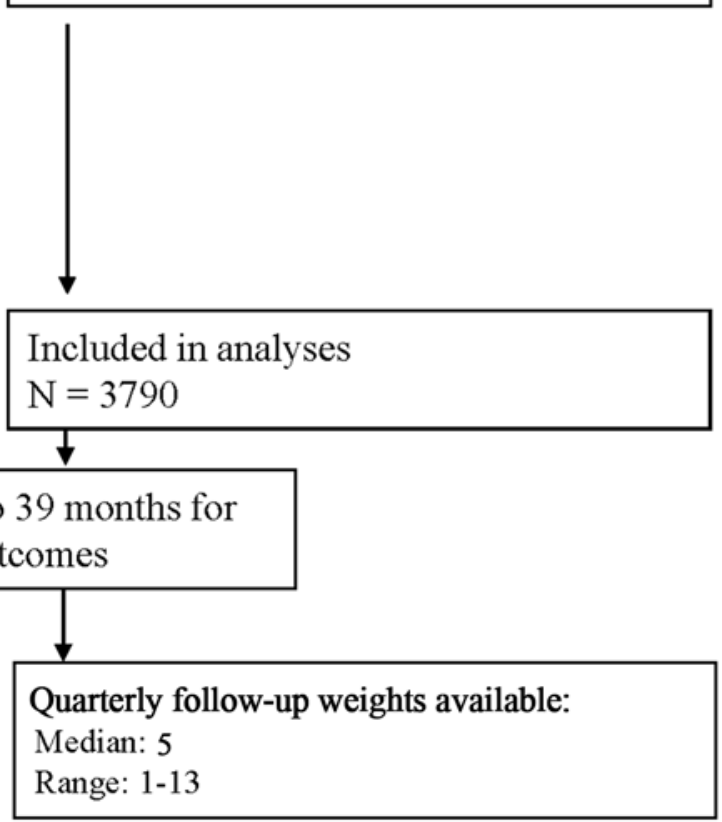

Figure 1.

Flow diagram of exclusions and study design of persons with amputation and frequency-matched nondisabled cohort. ${ }^{\S}$ For persons with amputation, baseline defined as median of weights measured 2-8 wk after index amputation, or if not available, median of weights measured in 8 wk prior to amputation after subtracting predicted/estimated weight of limb loss (see Appendix, available online only). ${ }^{\ddagger}$ Disqualifying amputations were those that occurred at level higher than toe $<18$ mo after baseline $(n=53)$. ICD-9= International Classification of Diseases-9th edition, VA = Department of Veterans Affairs. 
who were frequency matched (5:1) to persons with amputation based on (1) diabetes, (2) BMI (further explained subsequently), (3) age (in categories reflecting the age range of the persons with amputation), and (4) calendar year (see Figure 1 for more details). For matching purposes, BMI in persons with limb loss was based on their preamputation weight (Appendix, available online only). The reference date for persons without amputation was the first date that they had the matching factors and a weight record available. Persons without amputation who died $<18$ mo after their reference date or who did not have any weight measures 2 wk to 39 mo after baseline were not eligible for inclusion.

\section{Weight, Height, and Body Mass Index}

We used weights and heights obtained during inpatient and outpatient clinical encounters.

Since we were not interested in assessing weight changes because of limb loss, in persons with an amputation baseline weight was the median of weights obtained 2 to 8 wk after their index amputation. We selected this time period because weights often fluctuate in the first $2 \mathrm{wk}$ after an amputation due to changes in fluid balance. We divided follow-up time into 3 mo intervals and calculated the median recorded weight for each individual during each time interval for a maximum of 13 possible weight measurements per person during 39 mo of follow-up, or until the last day when data were available at the time this study was conducted (August 31, 2010), whichever was later, permitting a minimum of 20 mo of follow-up for all study participants.

To address the potential problem of measurement and/or data entry errors, we used a multistep process to clean and select apparently valid weights and heights (Appendix). Among individuals with multiple height measures over time, the modal height was used to calculate BMI.

Percent weight change, calculated as the difference between weight at time $x$ and weight at baseline, divided by baseline weight $\times 100$, was the primary outcome of interest.

\section{Other Covariates}

Demographic information (e.g., age, marital status, and race) was obtained from the VISN 20 Data Warehouse. We recorded the service-connected disability (SCD) percentage as a measure of functional impairment as it relates to an individual's military service. SCD per- centage is associated with physical and mental health status and has been used as a proxy for socioeconomic status and disease severity [12]. Veterans with an SCD of 50 percent or higher qualify for healthcare and prescriptions without copayment. Comorbidity was assessed via diagnostic cost group (DCG) score. DCG is computed as a ratio of the person's cost to the average cost in the entire Medicare population [13-14]. The DCG of the Medicare population average is calibrated to be 1 ; a DCG $>1$ indicates greater costs than the average Medicare patient. The VA national average DCG is 0.7 based on fiscal year 2006 claims. ${ }^{*}$

\section{Statistical Methods}

Descriptive analyses include the presentation, by level of amputation, of percentages (for categorical variables) and medians and interquartile ranges (for continuous variables) for demographic, amputation-related and healthrelated characteristics. The distributions of 1,2 , and $3 \mathrm{yr}$ percent weight changes (relative to baseline) were summarized using the following categories: $>5$ percent weight loss, 5 percent weight loss to $<5$ percent weight gain ("stable weight"), 5 to $<10$ percent weight gain, and $\geq 10$ percent weight gain. To explore the shape of trajectories of percent weight change over time, we used nonparametric smoothing plots, overall and for different covariate subgroups. The "lowess" smoother uses locally weighted regression to fit a smooth curve representing average percent weight change as a function of time [15]. In parametric linear regression modeling of (continuous) percent weight change from baseline, we included time in months after the index amputation and time squared (to allow for nonlinear trends) as continuous variables. Because percent weight change was, by definition, zero for all subjects at baseline (time $=0$ ), we fitted models without an intercept term. The effect of amputation status and matching variables (see Figure 1) was modeled by interactions with time. In addition, we included a three-way interaction of amputation level with BMI and time to allow for the possibility that the association between BMI and percent weight change varied by amputation level. Repeated measurements within person were accommodated using generalized estimating equations.

\footnotetext{
*Sophie Lo (Management and Program Analyst, VA, Office of Informatics and Analytics, Washington, DC). Personal communication with: Alyson J. Littman (Seattle Epidemiologic Research and Information Center, VA Puget Sound Health Care System, Seattle, WA). 2008 Oct 1.
} 
We conducted a number of sensitivity analyses to evaluate the robustness of our findings. Since it was also reasonable to consider absolute (rather than percent) weight change as the outcome measure, we examined regression models with weight as the outcome measure. Because comorbidities and overall health status may differ between those with and without an amputation and may be associated with weight change, we conducted further analyses adjusting for disease burden as measured by DCG (in categories). We also conducted analyses limited to those who lived at least 39 mo after baseline. Finally, because of the imbalance in numbers of weights, we created a dichotomous variable ( $\geq 3$ follow-up weight measures including $\geq 1$ follow-up weight measure(s) from year 2 or 3 [more complete follow-up] vs not [less complete follow-up]) and analyzed results in those with more complete follow-up. Results from all sensitivity analyses were qualitatively similar to our main model results; consequently, we focus our presentation on our primary analyses. Statistical analyses were conducted using Stata 13.1 (StataCorp LP; College Station, Texas), and statistical significance was based on a $p<0.05$.

\section{RESULTS}

A total of 759 men with incident amputations met the inclusion criteria (Figure 1). To form the comparison group of men without an amputation, we matched 5:1 on the factors described in the "Methods" section; we were unable to find a match for one person, leaving a total of 3,790 men.

As expected based on our matching, the distribution of ages, BMI, reference years, and presence of a diabetes diagnosis was similar between persons with and without an amputation: 65 percent of individuals were between the ages of 55 and $74 \mathrm{yr}, 73$ percent had diabetes, and 40 percent were obese (Table 1). Compared with men without an amputation, a greater proportion of individuals with an amputation had a $\geq 50$ percent SCD rating, had DCG $>1$, and died or were censored during followup. Median number of follow-up measures was greater in persons with amputation than persons without amputation (7 vs 5), and among persons with amputation, was greater among those with a PFA than a TFA (medians of 8 and 5, respectively). However, the median number of measures was stable over time in persons without amputation (median of 2 measures each year), while it decreased over time in persons with amputation (median of 4 in year 1, 2 in year 2, and 1 in year 3; data not presented), such that 35.7 percent of men with amputation (vs 19.9\% of men without amputation) did not have a measure in year 3 . When considering a composite measure of number of measures and duration of record, a similar proportion of those with and without an amputation (66\% and 68\%, respectively) had more complete follow-up, as defined in the "Methods" section (chisquare $p=0.26$ ).

The most frequent diagnoses present at the time of amputation were diabetes (72.1\%), peripheral vascular disease (64.2\%), and local significant infection (60.2\%). Only 12.9 percent had a diagnosis code indicating trauma, and 0.6 percent had a code indicative of a lowerlimb cancer. Diabetes was less common and peripheral vascular disease diagnosis was more common in men with a TFA (55.2\% and $74.0 \%$, respectively) than men with a more distal amputation (data not presented).

In unadjusted analyses, mean percent weight change and the proportion of men gaining $\geq 10$ percent of their baseline weight approximately 1,2 , and 3 yr after baseline was greater in men with amputation versus without, and among men with an amputation, it was greater in those with a TTA and TFA than a PFA (Tables $\mathbf{2}$ and $\mathbf{3}$ ). Over 45 percent of men who had a TTA or a TFA gained $\geq 10$ percent of their body weight by the end of the second year of follow-up, compared with 9.2 percent of men without amputation and 22.7 percent of men with a PFA (Table 3). By the end of the third year of follow-up, the percentage of individuals who gained $\geq 10$ percent of body weight was similar to those at the end of the second year, but there was a slight increase in the proportion of individuals who lost $\geq 5$ percent of their body weight since baseline (18.5\% among men without amputation and $19.7 \%, 13.0 \%$, and $22.5 \%$ among men with a PFA, TTA, and TFA, respectively).

As shown in Figure 2, in the first 2 yr of follow-up, mean estimated percentage weight gain in men with amputation was considerably greater than in men without amputation. Weight gain peaked in the second year, followed by weight loss from the peak but not a return to baseline weight, except in men without amputation. In men with an amputation, at each time point, mean percent weight change was greater among men with a TTA and TFA than men with a PFA. Percent weight changes in men with a TTA and TFA were not statistically significant different from each other at any time point. 
JRRD, Volume 52, Number 2, 2015

Table 1.

Characteristics of male veterans with and without lower-limb amputation.

\begin{tabular}{|c|c|c|c|c|c|c|c|c|c|c|}
\hline \multirow{3}{*}{ Characteristic } & \multirow{2}{*}{\multicolumn{2}{|c|}{$\begin{array}{c}\text { Amputation } \\
\text { Absent } \\
(N=3,790)\end{array}$}} & \multirow{2}{*}{\multicolumn{2}{|c|}{$\begin{array}{c}\text { Amputation } \\
\text { Present } \\
(N=759)\end{array}$}} & \multicolumn{6}{|c|}{ Level of Amputation } \\
\hline & & & & & \multicolumn{2}{|c|}{$\begin{array}{c}\text { Partial Foot } \\
N=396(52.2 \%)\end{array}$} & \multicolumn{2}{|c|}{$\begin{array}{c}\text { Transtibial } \\
N=267(35.2 \%)\end{array}$} & \multicolumn{2}{|c|}{$\begin{array}{c}\text { Transfemoral } \\
N=96(12.6 \%)\end{array}$} \\
\hline & $n$ & $\%$ & $n$ & $\%$ & $n$ & $\%$ & $n$ & $\%$ & $n$ & $\%$ \\
\hline \multicolumn{11}{|l|}{ Age (yr) } \\
\hline$<55$ & 705 & 18.6 & 141 & 18.6 & 77 & 19.4 & 52 & 19.5 & 12 & 12.5 \\
\hline $55-64$ & 1,470 & 38.8 & 294 & 38.7 & 152 & 38.4 & 110 & 41.2 & 32 & 33.3 \\
\hline $65-74$ & 995 & 26.3 & 200 & 26.4 & 106 & 26.8 & 63 & 23.6 & 31 & 32.3 \\
\hline $75-89$ & 620 & 16.4 & 124 & 16.3 & 61 & 15.4 & 42 & 15.7 & 21 & 21.9 \\
\hline \multicolumn{11}{|l|}{ Reference Years } \\
\hline 1997-2000 & 555 & 14.6 & 111 & 14.6 & 35 & 8.8 & 60 & 22.5 & 16 & 16.7 \\
\hline 2001-2002 & 670 & 17.7 & 134 & 17.7 & 69 & 17.4 & 48 & 18.0 & 17 & 17.7 \\
\hline 2003-2004 & 775 & 20.4 & 156 & 20.6 & 91 & 23.0 & 48 & 18.0 & 17 & 17.7 \\
\hline 2005-2006 & 880 & 23.2 & 176 & 23.2 & 94 & 23.7 & 55 & 20.6 & 27 & 28.1 \\
\hline 2007-2008 & 910 & 24.0 & 182 & 24.0 & 107 & 27.0 & 56 & 21.0 & 19 & 19.8 \\
\hline \multicolumn{11}{|l|}{ Percent Service Connected ${ }^{*}$} \\
\hline$<50$ & 2,826 & 74.6 & 488 & 64.3 & 263 & 66.4 & 166 & 62.2 & 59 & 61.5 \\
\hline$\geq 50$ & 964 & 25.4 & 271 & 35.7 & 133 & 33.6 & 101 & 37.8 & 37 & 38.5 \\
\hline \multicolumn{11}{|l|}{ Diabetes Diagnosis } \\
\hline No & 1,010 & 26.6 & 203 & 26.8 & 86 & 21.7 & 74 & 27.7 & 43 & 44.8 \\
\hline Yes & 2,780 & 73.4 & 556 & 73.3 & 310 & 78.3 & 193 & 72.3 & 53 & 55.2 \\
\hline \multicolumn{11}{|l|}{ Diagnostic Cost Group Score $^{\dagger}$} \\
\hline$<1$ & 3,093 & 82.0 & 9 & 1.2 & 6 & 1.5 & 2 & 0.7 & 1 & 1.0 \\
\hline $1-1.9$ & 563 & 14.9 & 104 & 13.7 & 69 & 17.4 & 26 & 9.7 & 9 & 9.4 \\
\hline $2-2.9$ & 84 & 2.2 & 260 & 34.3 & 146 & 36.9 & 87 & 32.6 & 27 & 28.1 \\
\hline$\geq 3$ & 34 & 0.9 & 386 & 50.9 & 175 & 44.2 & 152 & 56.9 & 59 & 61.5 \\
\hline \multicolumn{11}{|l|}{ Time until Censoring or Death } \\
\hline Censored 18-30 mo post baseline & 456 & 12.0 & 171 & 22.5 & 89 & 22.5 & 54 & 20.2 & 28 & 29.2 \\
\hline Censored 30-39 mo post baseline & 409 & 10.8 & 119 & 15.7 & 64 & 16.2 & 38 & 14.2 & 17 & 17.7 \\
\hline Amputation-free survival $\geq 39$ mo & 2,925 & 77.2 & 469 & 61.8 & 243 & 61.4 & 175 & 65.5 & 51 & 53.1 \\
\hline \multicolumn{11}{|l|}{ Body Mass Index $\left(\mathrm{kg} / \mathrm{m}^{2}\right)^{\S}$} \\
\hline$<25$ & 935 & 24.7 & 187 & 24.6 & 93 & 23.5 & 60 & 22.5 & 34 & 35.4 \\
\hline $25.0-29.9$ & 1,325 & 35.0 & 265 & 34.9 & 139 & 35.1 & 91 & 34.1 & 35 & 36.5 \\
\hline$\geq 30$ & 1,530 & 40.4 & 307 & 40.4 & 164 & 41.4 & 116 & 43.4 & 27 & 28.1 \\
\hline \multicolumn{11}{|l|}{$\begin{array}{l}\text { No Follow-Up Weight Measures } \\
\text { Available In Given Time Interval }\end{array}$} \\
\hline Year 1 & 290 & 7.7 & 30 & 4.0 & 11 & 2.8 & 11 & 4.1 & 8 & 8.3 \\
\hline Year 2 & 607 & 16.0 & 116 & 15.3 & 50 & 12.6 & 43 & 16.1 & 23 & 24.0 \\
\hline Year 3 & 754 & 19.9 & 271 & 35.7 & 131 & 33.1 & 93 & 34.8 & 47 & 49.0 \\
\hline
\end{tabular}

Table 4 presents mean percent weight change estimates and 95 percent confidence intervals from the multivariable model at 12, 24, and 36 mo follow-up, stratified by baseline BMI $\left(25,30\right.$, and $\left.35 \mathrm{~kg} / \mathrm{m}^{2}\right)$. For men without amputation and men with a PFA and TTA, mean percent weight change decreased with increasing preamputation BMI (though the differences were not statistically significant for men with a TTA at 3 yr followup). For men with a TFA, percent weight change was similar across preamputation BMI levels. 
Table 2.

Unadjusted (observed) percentage weight changes from baseline.

\begin{tabular}{|c|c|c|c|c|c|c|c|c|}
\hline \multirow{3}{*}{ Time Window* } & \multirow{2}{*}{\multicolumn{2}{|c|}{ No Amputation }} & \multicolumn{6}{|c|}{ Level of Amputation } \\
\hline & & & \multicolumn{2}{|c|}{ Partial Foot } & \multicolumn{2}{|c|}{ Transtibial } & \multicolumn{2}{|c|}{ Transfemoral } \\
\hline & $\mathbf{M}$ & IQR & $\mathbf{M}$ & IQR & $\mathbf{M}$ & IQR & $\mathbf{M}$ & IQR \\
\hline$\sim 2 \mathrm{yr}$ & 0.5 & $-3.2,4.6$ & 3.2 & $-2.2,8.9$ & 8.4 & $0.1,16.0$ & 9.8 & $1.2,17.0$ \\
\hline$\sim 3 \mathrm{yr}$ & 0.5 & $-3.6,4.7$ & 2.2 & $-2.9,9.5$ & 9.7 & $-0.1,18.0$ & 9.7 & $0.6,17.0$ \\
\hline
\end{tabular}

Note: See Table 1 for $N$ at each time interval.

* Time windows for $\sim 1, \sim 2$, and 3 yr: 10-18 mo, 22-30 mo, and 31-39 mo, respectively.

IQR = interquartile range, $\mathrm{M}=$ median.

Table 3.

Unadjusted (observed) categories of percentage weight changes.

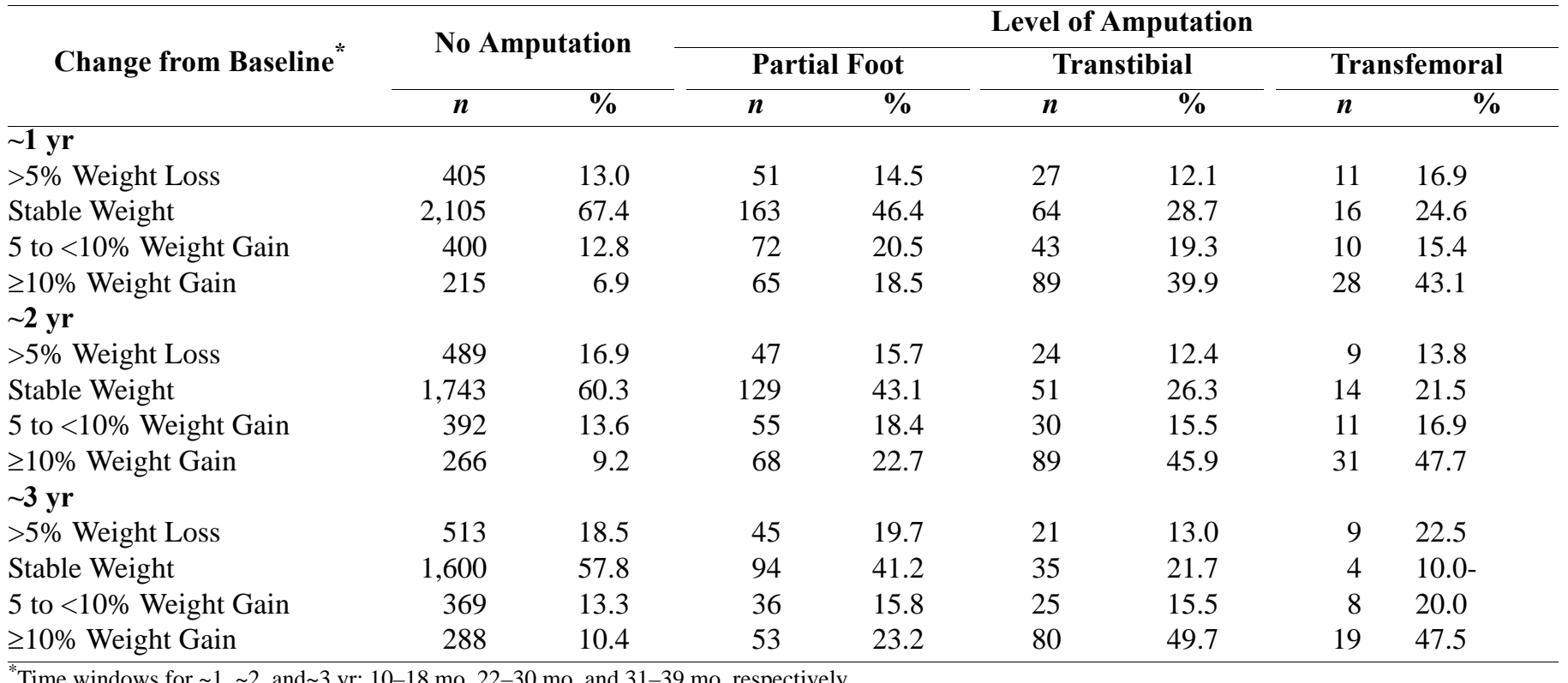

"Time windows for $\sim 1, \sim 2$, and 3 yr: 10-18 mo, 22-30 mo, and 31-39 mo, respectively.

\section{DISCUSSION}

Excess weight gain can have both immediate and long-term adverse consequences in people with LLA. Data from our study indicate that weight gain in the $2 \mathrm{yr}$ after amputation is substantial. Specifically, men with more proximal amputations (e.g., TTA and TFA) gained more weight after amputation, approximately 8 to 9 percent body weight (7-8 kg [16-18 lb], assuming a starting weight of $90 \mathrm{~kg}$ [200 lb]) than men with a more distal amputation (approximately $3 \%-6 \%$ or $3-4 \mathrm{~kg}$ [6-8 lb]). Furthermore, weight gain in men with a PFA (and all other amputation groups) was significantly more than in a demographically similar population of men without an amputation. Generally, weight gain peaked at around
2 yr, followed by weight loss. However, estimates in the third year were relatively imprecise because of missing data. For men with PFA and TTA (but not men with a TFA), percent weight gain was inversely proportional to baseline BMI.

Although our data were inadequate for understanding the mechanisms behind the weight changes, there are a number of plausible explanations. Weight gain in the first 2 yr after amputation may have occurred because of decreased activity and/or overeating. Other investigators have found the most popular leisure time activities among people with LLA were sedentary (e.g., watching television, going to restaurants, and playing cards) even in individuals who were active before their amputation [16]. The wound healing process may take weeks or 
JRRD, Volume 52, Number 2, 2015

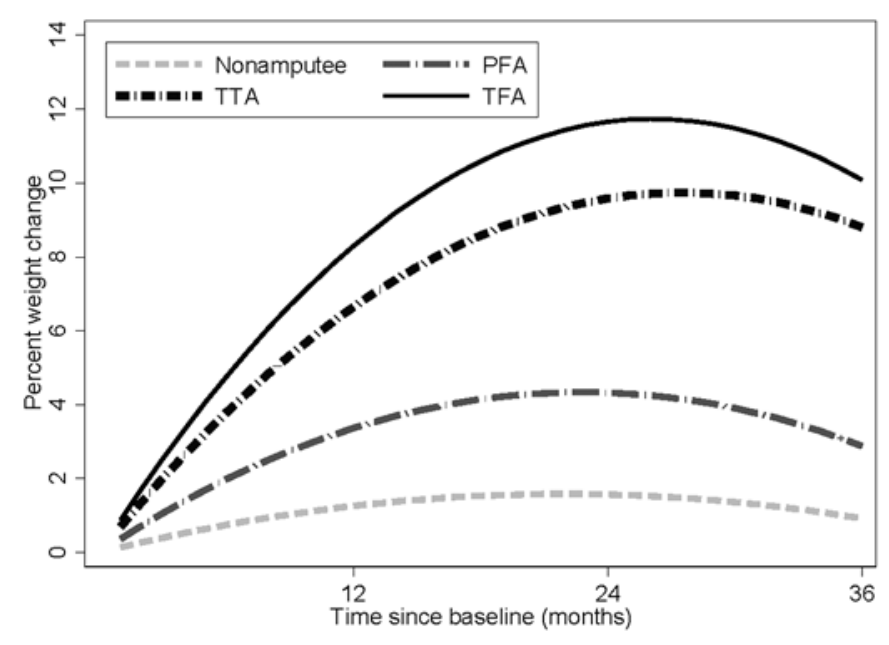

Figure 2.

Estimated mean percent weight change from baseline by amputation group. Predicted percent weight change estimates are based on linear regression model that used generalized estimating equations to account for within-person correlation. Model included parameters for time and time squared and interactions of time and time squared with age $(<55,55-64,65-74$, $\geq 75 \mathrm{yr}$ ), diabetes, reference year, amputation level (none, partial foot amputation [PFA], transtibial amputation [TTA], transfemoral amputation [TFA]), body mass index (BMI) (continuous, centered at the mean of 30) and BMI $\times$ amputation level. Estimates presented are for reference years 2001-2002, 55-64 yr, with diabetes and $\mathrm{BMI}=30$.

months, and individuals may be unable or unmotivated to be physically active at this time. Additionally, it may take up to 12 mo to obtain a properly fitting prosthesis, and physical activity tends to decrease during this time [17]. Barriers related to prosthesis fitting are likely more limiting for people with a TTA and TFA than a PFA and may explain the differential weight gain by amputation level. Comorbid depression, which is highly prevalent in this population [18-19], may also contribute to inactivity and overeating. Our prior work suggested that high BMI and weight gain are associated with impaired mobility [11], resulting in lower levels of physical activity. The inverse association between preamputation BMI and relative weight gain may be because those with a lower BMI preamputation may have been more active and decreased their activity more postamputation than those with a higher BMI, though future studies are needed to replicate and better understand this finding. The slowing of weight gain and possible weight loss in the third year may be explained by improvement in depressive symptoms [19] as individuals come to accept their amputation and become more adept and comfortable with ambulating and increase their physical activity. An alternative explanation for the weight loss is illness; though we constructed our study to include a healthier population, mortality is high in this population.

We are aware of only one other study that investigated weight change following amputation [11]. In that study, mean weight gain in 87 people with a dysvascular major amputation was $6 \mathrm{lb}$ over 12 mo, which is somewhat less than that observed in this study and may reflect different inclusion criteria [11]. Nevertheless, the two studies are in agreement regarding the direction of weight change. Our study builds on the prior literature by documenting, in a relatively heterogeneous population that included amputations from multiple etiologies, how percent weight change varies by amputation level and preamputation BMI and provides comparative data in demographically similar men without an amputation. Together, these studies highlight the magnitude of this problem, reinforce the detrimental consequences of excess weight gain, and indicate a need for further research to identify effective weight management interventions.

While use of medical record data allowed assessment of weight change on a relatively large, population-based sample of VA users, it also led to a number of limitations. The weight data were obtained from routine clinical practice and not collected at predefined time intervals using standardized data collection procedures as would be specified in a study protocol. To eliminate weights that might introduce statistical noise and reduce our ability to detect patterns, we carefully cleaned the data before selecting median values. However, when individuals had few weights, it was more difficult to identify and remove plausible but potentially erroneous weights. Additionally, the availability of recorded weights varied in this population; some men had weight data in year 1 only, while others had measurements in all years. While our modeling technique allowed us to take greatest advantage of the data that were available, substantial missing data in the third year of follow-up resulted in less precision in these estimates, and this was particularly evident in men with a TFA. In sensitivity analyses comparing weight changes in those with more versus fewer weight measures, the prevailing trends of overall weight gain were apparent, though less marked. The attenuation of weight gain may 
Table 4.

Predicted percent weight changes from baseline at 12, 24, and 36 mo in persons with and without a lower-limb amputation with body mass index $(\mathrm{BMI})=25,30$, and $35 \mathrm{~kg} / \mathrm{m}^{2}$.

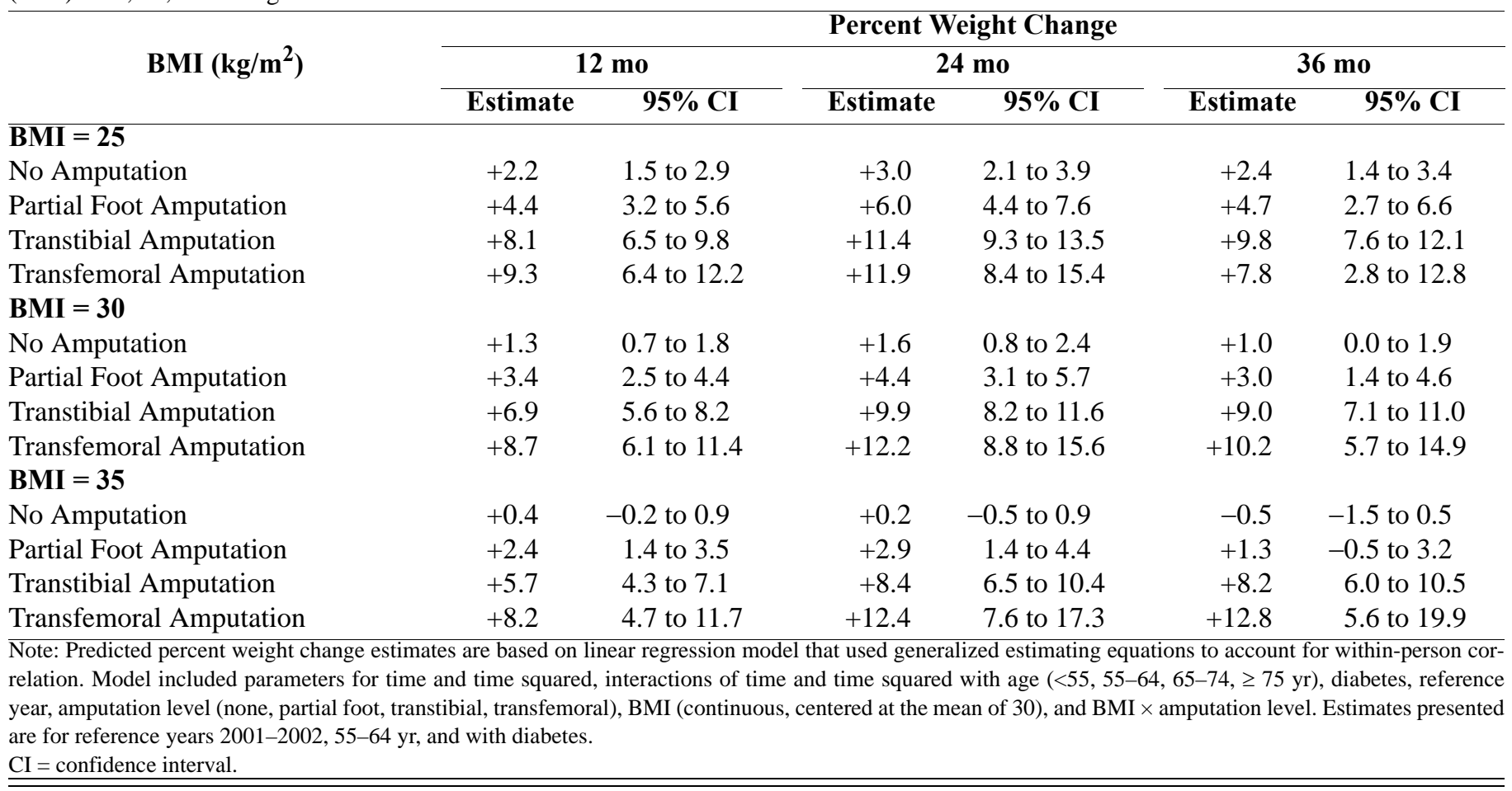

be because approximately 13 percent of persons with amputation died in the 18 to 39 mo after baseline (see Appendix, Table 1), and death is typically preceded by weight loss. Thus, our findings are likely more reflective of the healthier population of people with lower-limb loss. Furthermore, it was not possible to determine whether weight was measured with the individual wearing his prosthesis, how much that prosthesis weighed, and if prosthesis use changed over time. However, the mean weight gain observed at $2 \mathrm{yr}$ in persons with a TTA and TFA was on average more than the potential error introduced by a prosthesis (which weighs approximately 3 and $5 \mathrm{~kg}$, respectively, for a transtibial and transfemoral prosthesis) and cannot explain any of the weight gain observed in men with a PFA. Future longitudinal studies employing standardized assessment of weight, body composition measures, physical activity, and comorbidities could eliminate the errors noted here and would also be helpful in expanding our understanding of the predictors of body weight changes and may help to identify targets for intervention. Finally, though we constructed a comparison cohort of individuals who were very similar to the persons with amputation in terms of age, reference year, BMI, and diabetes, there were large differences in their morbidity, as assessed by DCG scores and the percent that died during follow-up. However, results from sensitivity analyses adjusting for DCG were similar.

\section{CONCLUSIONS}

It is well documented that obesity is related to many health conditions to which this sample is susceptible, including additional amputations, heart disease, and stroke [20]. Thus, using the time of amputation to promote improved lifestyle habits and weight loss could result in a range of physical, mental, and social benefits. Our preliminary findings suggest that LLA is often followed by clinically important weight gain, but future studies will need to verify our results using standardized measures of BMI, larger samples, and longer follow-up periods. It would also be informative to measure lifestyle habits such as physical activity, mode of ambulation (e.g., prosthesis, crutches, manual wheelchair, motorized wheelchair), sedentary behaviors, dietary behaviors, and health status changes in order to accurately identify the 
likely causal factors. Finally, future studies are also needed to determine whether promoting weight loss following amputation is feasible and can result in health and quality of life benefits.

\section{ACKNOWLEDGMENTS}

\section{Author Contributions:}

Study concept and design: A. J. Littman, M. L. Thompson, D. E. Arterburn, E. Bouldin, J. K. Haselkorn, B. J. Sangeorzan, E. J. Boyko.

Analysis and interpretation of data: A. J. Littman, M. L. Thompson, D. E. Arterburn, E. Bouldin, J. K. Haselkorn, B. J. Sangeorzan, E. J. Boyko.

Drafting of manuscript: A. J. Littman.

Critical revision of manuscript for important intellectual content:

A. J. Littman, M. L. Thompson, D. E. Arterburn, E. Bouldin,

J. K. Haselkorn, B. J. Sangeorzan, E. J. Boyko.

Statistical analysis: A. J. Littman.

Obtained funding: A. J. Littman.

Administrative, technical, or material support: A. J. Littman, M. L. Thompson, D. E. Arterburn, E. Bouldin, J. K. Haselkorn, B. J. Sangeorzan, E. J. Boyko.

Study supervision: A. J. Littman.

Financial Disclosures: The authors have declared that no competing interests exist.

Funding/Support: This material was based on work supported in part by the VA Office of Research and Development Cooperative Studies Program. The Seattle Epidemiologic Research and Information Center of the VA provided support for this research. Dr. Littman's time was also supported by a VA Rehabilitation Research and Development Career Development Award (grant 6982).

Additional Contributions: Dr. Bouldin is now with the VA Center of Innovation for Veteran-Centered and Value-Driven Care, Seattle, Washington.

Institutional Review: The Institutional Review Board at the VA Puget Sound Health Care System approved this study and granted a waiver of written informed consent to review patient records.

Disclaimer: The contents do not represent the views of the VA or the U.S. Government.

\section{REFERENCES}

1. Ziegler-Graham K, MacKenzie EJ, Ephraim PL, Travison TG, Brookmeyer R. Estimating the prevalence of limb loss in the United States: 2005 to 2050. Arch Phys Med Rehabil. 2008;89(3):422-29. [PMID:18295618] http://dx.doi.org/10.1016/j.apmr.2007.11.005

2. Dillingham TR, Pezzin LE, MacKenzie EJ. Limb amputation and limb deficiency: Epidemiology and recent trends in the United States. South Med J. 2002;95(8):875-83. [PMID:12190225]
3. Ma VY, Chan L, Carruthers KJ. Incidence, prevalence, costs, and impact on disability of common conditions requiring rehabilitation in the United States: Stroke, spinal cord injury, traumatic brain injury, multiple sclerosis, osteoarthritis, rheumatoid arthritis, limb loss, and back pain. Arch Phys Med Rehabil. 2014;95(5):986-995.e1.

[PMID:24462839]

http://dx.doi.org/10.1016/j.apmr.2013.10.032

4. Hrubec Z, Ryder RA. Traumatic limb amputations and subsequent mortality from cardiovascular disease and other causes. J Chronic Dis. 1980;33(4):239-50.

[PMID:7358826] http://dx.doi.org/10.1016/0021-9681(80)90068-5

5. Modan M, Peles E, Halkin H, Nitzan H, Azaria M, Gitel S, Dolfin D, Modan B. Increased cardiovascular disease mortality rates in traumatic lower limb amputees. Am J Cardiol. 1998;82(10):1242-47. [PMID:9832102] http://dx.doi.org/10.1016/S0002-9149(98)00601-8

6. Yekutiel M, Brooks ME, Ohry A, Yarom J, Carel R. The prevalence of hypertension, ischaemic heart disease and diabetes in traumatic spinal cord injured patients and amputees. Paraplegia. 1989;27(1):58-62. [PMID:2784200] http://dx.doi.org/10.1038/sc.1989.9

7. National Institutes of Health. Clinical Guidelines on the Identification, Evaluation, and Treatment of Overweight and Obesity in Adults-The Evidence Report. National Institutes of Health. Obes Res. 1998;6(Suppl 2):51S-209S. [PMID:9813653]

8. Fabricatore AN, Wadden TA. Obesity. Annu Rev Clin Psychol. 2006;2:357-77. [PMID:17716074]

http://dx.doi.org/10.1146/annurev.clinpsy.2.022305.095249 Erratum in: Obes Res. 1998;6(6):464.

9. Kurdibaylo SF. Cardiorespiratory status and movement capabilities in adults with limb amputation. J Rehabil Res Dev. 1994;31(3):222-35. [PMID:7965880]

10. Rose HG, Schweitzer P, Charoenkul V, Schwartz E. Cardiovascular disease risk factors in combat veterans after traumatic leg amputations. Arch Phys Med Rehabil. 1987; 68(1):20-23. [PMID:3800619]

11. Rosenberg DE, Turner AP, Littman AJ, Williams RM, Norvell DC, Hakimi KM, Czerniecki JM. Body mass index patterns following dysvascular lower extremity amputation. Disabil Rehabil. 2013;35(15):1269-75.

[PMID:23094934] http://dx.doi.org/10.3109/09638288.2012.726690

12. Kazis LE, Miller DR, Clark J, Skinner K, Lee A, Rogers W, Spiro A 3rd, Payne S, Fincke G, Selim A, Linzer M. Health-related quality of life in patients served by the Department of Veterans Affairs: Results from the Veterans Health Study. Arch Intern Med. 1998;158(6):626-32. [PMID:9521227] http://dx.doi.org/10.1001/archinte.158.6.626 
13. Meenan RT, Goodman MJ, Fishman PA, Hornbrook MC, O’Keeffe-Rosetti MC, Bachman DJ. Using risk-adjustment models to identify high-cost risks. Med Care. 2003;41(11): 1301-12. [PMID:14583693] http://dx.doi.org/10.1097/01.MLR.0000094480.13057.75

14. Maciejewski ML, Liu CF, Fihn SD. Performance of comorbidity, risk adjustment, and functional status measures in expenditure prediction for patients with diabetes. Diabetes Care. 2009;32(1):75-80. [PMID:18945927] http://dx.doi.org/10.2337/dc08-1099

15. Cleveland WS. Robust locally weighted regression and smoothing scatterplots. J Am Stat Assoc. 1979;74:829-36. http://dx.doi.org/10.1080/01621459.1979.10481038

16. Couture M, Caron CD, Desrosiers J. Leisure activities following a lower limb amputation. Disabil Rehabil. 2010; 32(1):57-64. [PMID:19925277] http://dx.doi.org/10.3109/09638280902998797

17. Webster JB, Hakimi KN, Williams RM, Turner AP, Norvell DC, Czerniecki JM. Prosthetic fitting, use, and satisfaction following lower-limb amputation: A prospective study. J Rehabil Res Dev. 2012;49(10):1493-1504. [PMID:23516053]

18. Coffey L, Gallagher P, Horgan O, Desmond D, MacLachlan M. Psychosocial adjustment to diabetes-related lower limb amputation. Diabet Med. 2009;26(10):1063-67. [PMID:19900240] http://dx.doi.org/10.1111/j.1464-5491.2009.02802.x
19. Horgan O, MacLachlan M. Psychosocial adjustment to lower-limb amputation: A review. Disabil Rehabil. 2004; 26(14-15):837-50. [PMID:15497913] http://dx.doi.org/10.1080/09638280410001708869

20. Wang YC, McPherson K, Marsh T, Gortmaker SL, Brown M. Health and economic burden of the projected obesity trends in the USA and the UK. Lancet. 2011;378(9793): 815-25. [PMID:21872750] http://dx.doi.org/10.1016/S0140-6736(11)60814-3

Submitted for publication July 17, 2014. Accepted January 8, 2015.

This article and any supplementary material should be cited as follows:

Littman AJ, Thompson ML, Arterburn DE, Bouldin E, Haselkorn JK, Sangeorzan BJ, Boyko EJ. Lower-limb amputation and body weight changes in men. J Rehabil Res Dev. 2015;52(2):159-70. http://dx.doi.org/10.1682/JRRD.2014.07.0166

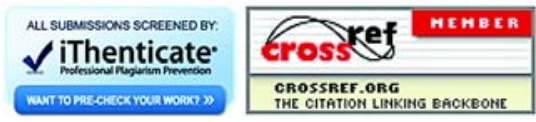


